\title{
Design of Ultra-wideband Textile Antenna for
}

\section{TV Broadcasting}

\author{
Euclides Lourenço Chuma \\ Yuzo Iano \\ Diego Pajuelo
}

Gabriel Gomes de Oliveira

\section{CITE THIS ARTICLE}

Chuma, Euclides Lourenço, Iano, Yuzo, Pajuelo, Diego, de Oliveira, Gabriel Gomes; 2019. Design of Ultra wideband Textile Antenna for TV Broadcasting. SET INTERNATIONAL JOURNAL OF BROADCAST ENGINEERING. ISSN Print: 2446-9246 ISSN Online: 2446-9432. doi: 10.18580/ setijbe.2019.9. Web Link: http://dx.doi.org/10.18580/setijbe.2019.9 


\title{
Design of Ultra-wideband Textile Antenna for TV Broadcasting
}

\author{
Euclides Lourenço Chuma, Yuzo Iano, Diego Pajuelo, Gabriel Gomes de Oliveira
}

\begin{abstract}
Digital television (DTV) has been adopted in many places throughout the world, and it is received in different device types, such as laptops, portable media players, and smartphones. However, the current antennas used in these devices to receive DTV channels have drawbacks, such as low performance and non-practical physical structure in many situations.

This paper presents a flexible, lightweight, and thin textile antenna for DTV, operating at an ultra-wideband (UWB) of $200 \mathrm{MHz}-800 \mathrm{MHz}$ and capable of being embedded in a garment or bag, making it easily transportable when folded. The antenna operation was simulated and measured to verify its performance, and based on the measurement results, the proposed flexible textile antenna was confirmed to have good performance, even in real conditions.
\end{abstract}

Index Terms - antenna, microstrip, TV, textile

\section{INTRODUCTION}

$\mathrm{A}$ NTENNAS are essential parts of television broadcasting systems. Integrating them into portable receivers is very challenging, mainly because of their dimensions and rigid structure. Therefore, a new generation of flexible and lightweight antennas integrated into garments or bags should be developed $[1,2]$.

This article proposes a flexible, lightweight, and thin textile antenna applied to broadcasting receivers and operating at an ultra-wideband (UWB) of $200 \mathrm{MHz}-800$ $\mathrm{MHz}$ to be embedded into portable devices. The antennas can be easily transported when folded or integrated into the physical structure of a large-format television (i.e., back cover).

The proposed antenna could be used as part of smart clothing $[2,3,4,5,6,7,8]$, which has received so much

This paragraph of the first footnote will contain the date on which you submitted your paper for review. It will also contain support information, including sponsor and financial support acknowledgment. For example, "This work was supported in part by the U.S. Department of Commerce under Grant BS123456".

E. L. Chuma, Department of Communications, School of Electrical and Computer Engineering, University of Campinas - UNICAMP, 13083-852, Campinas-SP, Brazil (e-mail: euclides.chuma@ieee.org).

Y. Iano, Department of Communications, School of Electrical and Computer Engineering, University of Campinas - UNICAMP, 13083-852, Campinas-SP, Brazil (e-mail: yuzo@decom.fee.unicamp.br).

D. Pajuelo, Department of Communications, School of Electrical and Computer Engineering, University of Campinas - UNICAMP, 13083-852, Campinas-SP, Brazil (e-mail: diego.pajuelo.castro@gmail.com)

G. Gomes de Oliveira, Department of Communications, School of Electrical and Computer Engineering, University of Campinas UNICAMP, 13083-852, Campinas-SP, Brazil (e-mail: oliveiragomesgabriel@live.com) attention due to the high interest in wearable electronics connected in a large network with other devices through the Internet of Things (IoT) $[9,10,11,12]$.

\section{ANTENNA DESIGN}

The proposed antenna uses a log-periodic structure, which is a member of structures known as frequency-independent antennas; these antennas have been studied for more than five decades $[13,14,15,16,17]$ and are still relevant because of their ability to maintain quasi-frequencyindependent characteristics over a wide band of frequencies $[18,19,20]$.

The log-periodic antennas have a very large bandwidth, with a reasonable gain, making them an excellent candidate for UWB systems. Therefore, because of these features, logperiodic antennas have been used for low-cost applications and a great broadband coverage.

The antenna structure shown in Fig. 1 is a planar logperiodic antenna proposed by DuHamel [13]. In the antenna, $\mathrm{R}_{1}=331.1 \mathrm{~mm}, \mathrm{R}_{2}=215.2 \mathrm{~mm}, \mathrm{\nabla}=0.65, \nabla=0.81, \nabla=45^{\circ}$, $\bigotimes=45^{\circ}$, and port gap width $=20 \mathrm{~mm}$.

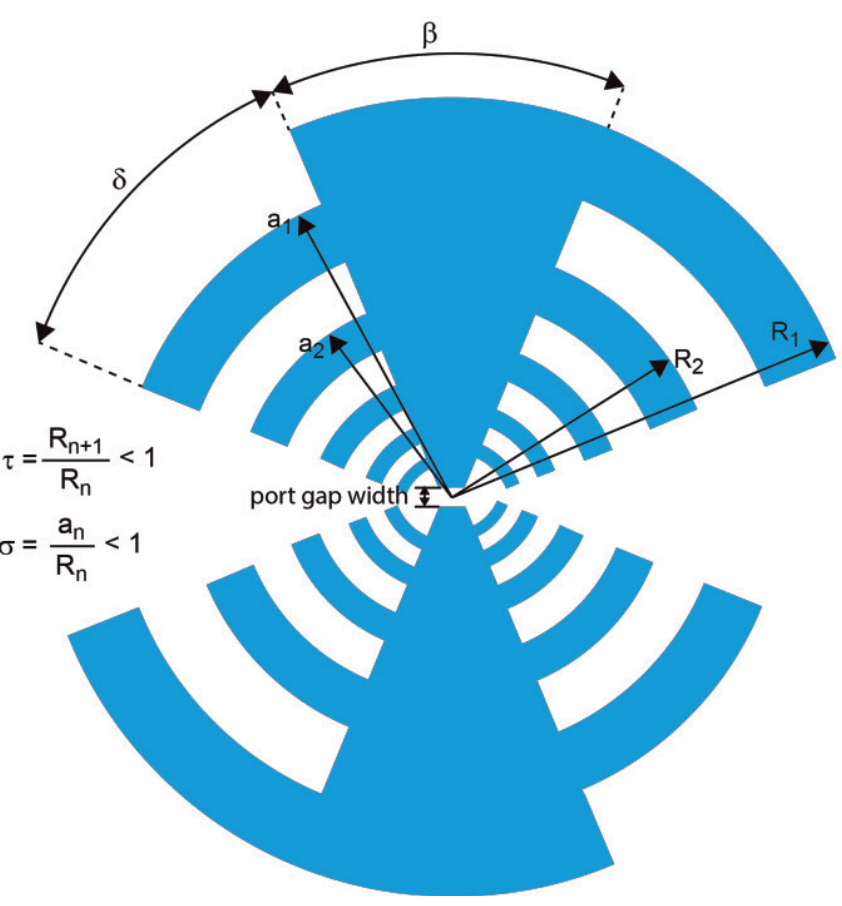

Fig. 1. Geometry structure of planar log-periodic antenna. 
The substrate material is a polyester clothing with relative permittivity $\otimes=3.2$ and thickness of $0.15 \mathrm{~mm}$. The conductor material used in the patch is a conductive fabric composed of $50 \%$ polyester and $50 \%$ silver-plated woven, as can be seen in Fig. 2.

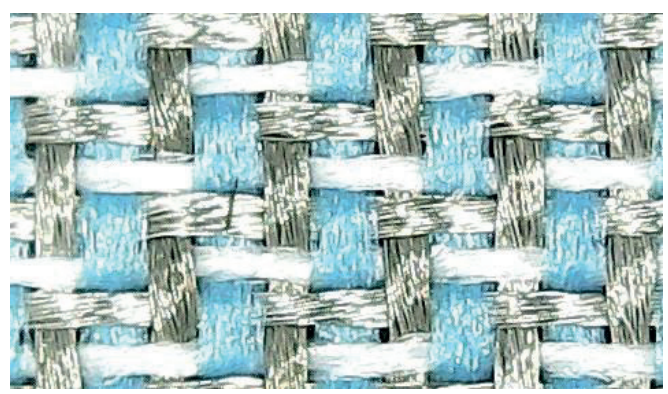

Fig. 2. Close-up image of the conductive textile used in the patch of the microstrip log-periodic antenna.

The structure of the conductive textile directly affects the surface resistivity. If the conductive paths in the woven are better aligned with the current direction, there will be less conductive loss [21,22]. It is also important to mention that elongation and/or compression of the textile decreases the geometric precision of the antenna shape and changes the antenna features, such as the resonance frequency and directivity gain [23].

The initial dimensions of the microstrip log-periodic antenna were calculated. Then, simulations were performed using the full-wave simulator ANSYS HFSS to obtain the most optimized antenna dimensions for operations between $200 \mathrm{MHz}$ and $800 \mathrm{MHz}$.

Figure 3 shows the model built in the simulator software and the simulated 3D radiation pattern. The simulation with a perfect electric conductor (PEC) presented an antenna gain of $\sim 5.7 \mathrm{~dB}$.

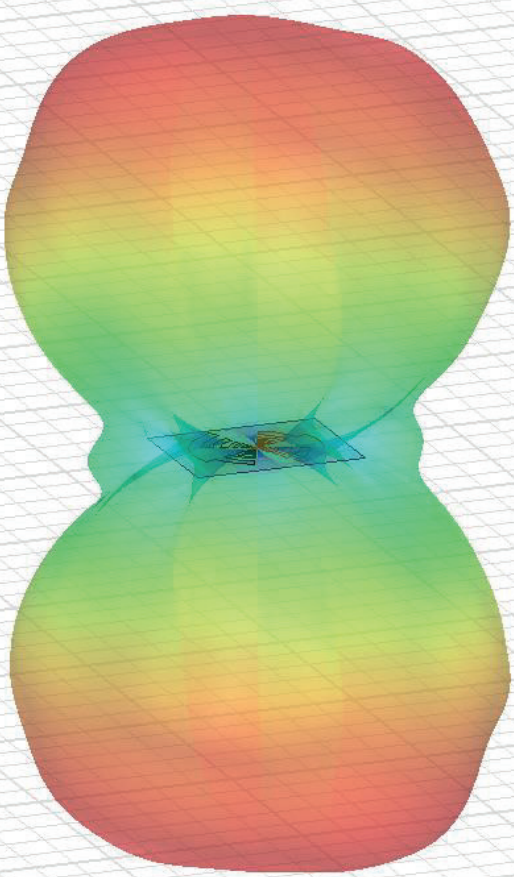

Fig. 3. Simulated 3D radiation pattern.

\section{MeAsurementS AND Results}

A prototype of the antenna was manufactured. The conductive textiles patches were cut and fixed into the polyester clothing substrate by sewing. Figure 4 shows the antenna prototype.

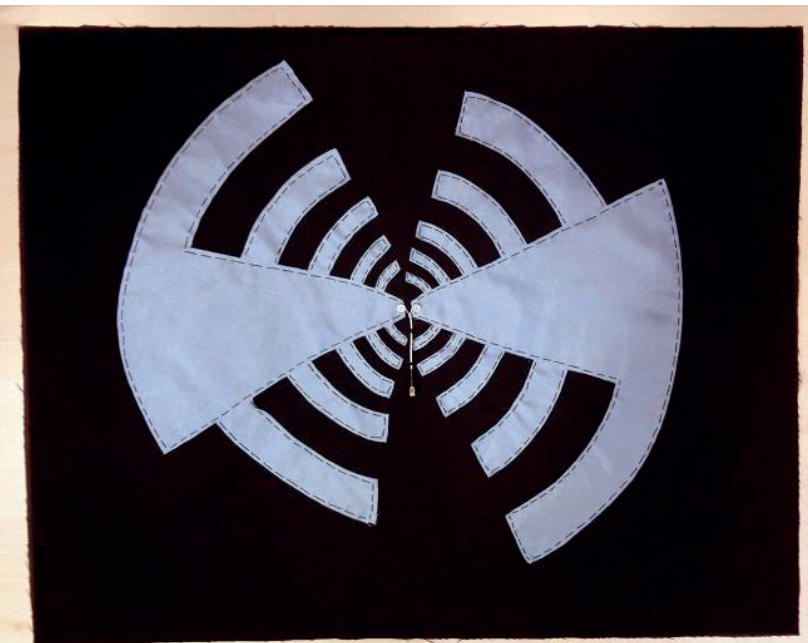

Fig. 4. Fabricated prototype of the antenna.

The performance of the antenna prototype was measured using a vector network analyzer (VNA) in order to obtain the S-parameters, as shown in Fig. 5.

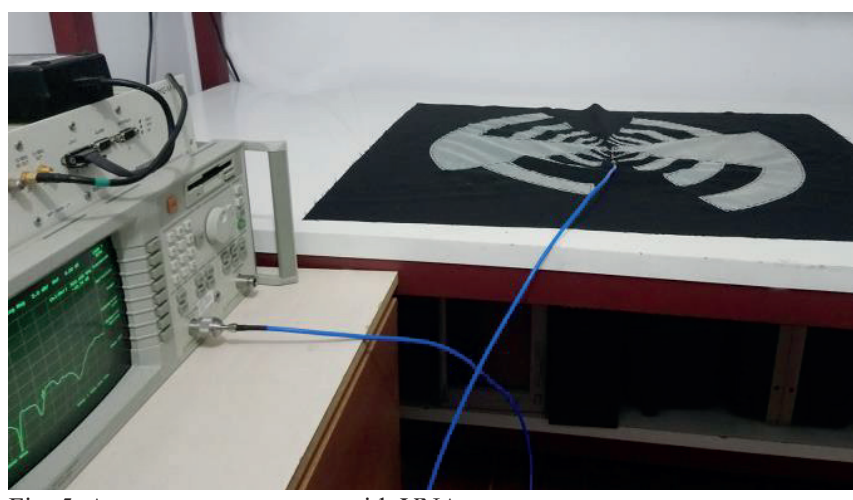

Fig. 5. Antenna measurement with VNA.

Figure 6 shows the antenna scattering parameters $\left(\mathrm{S}_{11}\right)$ according to the VNA measurement results and the electromagnetic simulation results.

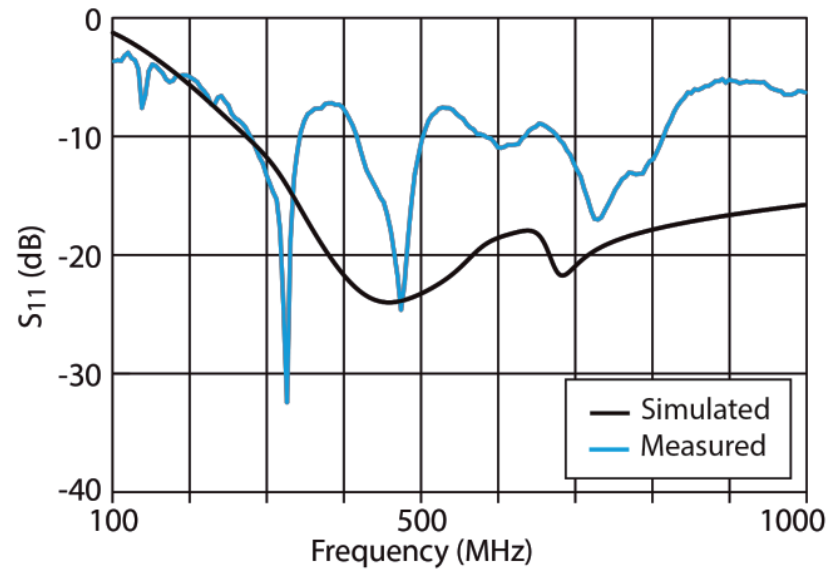

Fig. 6. Comparison of measured and simulated scattering parameters $\left(\mathrm{S}_{11}\right)$ of antenna. 
The measurements show an operating band for the antenna between $200 \mathrm{MHz}$ and $800 \mathrm{MHz}$. Figure 7 shows the reception of channel television. A balun matching transformer is used for practical conditions.

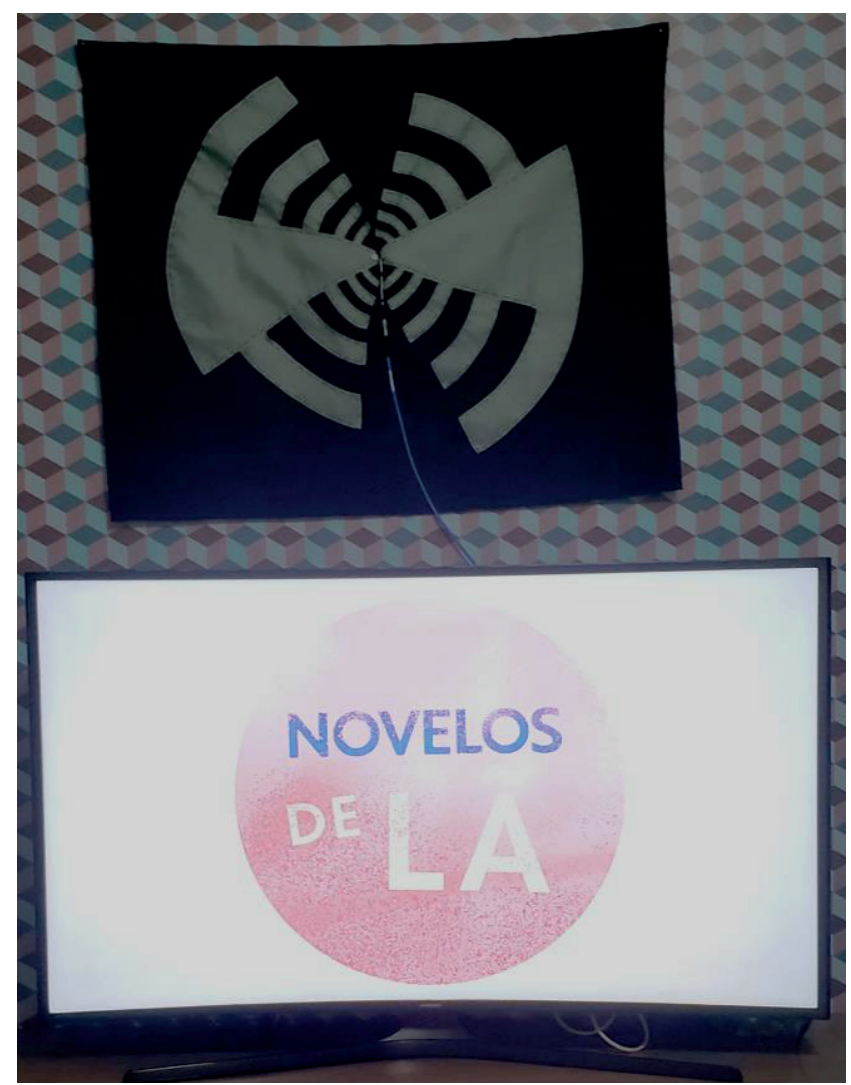

Fig. 7. Proposed antenna working with television.

The proposed antenna can be carried by the user and folded so that it occupies very little space. Figure 8 shows the prototype of the folded antenna.

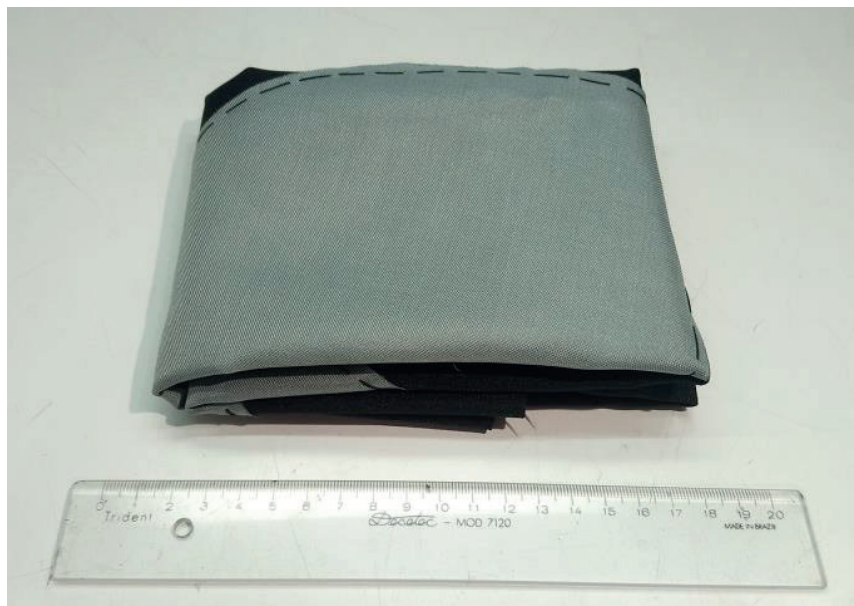

Fig. 7. Folded antenna.

\section{CONCLUSIONS}

This work developed and tested a textile UWB microstrip log-periodic antenna to be able to operate over a frequency range of $200 \mathrm{MHZ}-800 \mathrm{MHz}$. The proposed antenna is simple to manufacture and exhibits good flexibility. This paper presents a proven qualitative agreement between the experimental results and the numerical simulations. The differences are because PEC materials were used in the simulation models.

\section{REFERENCES}

[1] S. Lemey, S. Agneessens, H. Rogier, "Wearable Smart Objects: Microwaves Propelling Smart Textiles: A Review of Holistic Designs for Wireless Textile Nodes”, IEEE Microwave Magazine, 2018, v.19, i.6, pp. 83-100

[2] P. J. Soh, B. V. D. Bergh, H. Xu, H. Aliakbarian, et al., "A Smart Wearable Textile Array System for Biomedical Telemetry Applications", IEEE Transactions on Microwave Theory and Techniques, 2013, v.61, i.5, pp.2253-2261

[3] S. Seneviratne, Y. Hu, T. Nguyen, G. Lan, et al., A Survey of Wearable Devices and Challenges, IEEE Communications Surveys \& Tutorials, 2017, v.19, i.4, pp. 2573-2620

[4] J. Foroughi, T. Mitew, P. Ogunbona, R. Raad, F. Safaei, "Smart Fabrics and Networked Clothing: Recent developments in CNT-based fibers and their continual refinement", IEEE Consumer Electronics Magazine, 2016, v. 5, i. 4, pp. 105-111

[5] M. Chen, Y. Ma, Y. Li, D. Wu, Y. Zhang, C. Youn, "Wearable 2.0: Enabling Human-Cloud Integration in Next Generation Healthcare Systems", IEEE Communications Magazine, 2017, v. 55, i. 1, pp. 5461

[6] K. Nesenbergs, "Architecture of smart clothing for standardized wearable sensor systems", IEEE Instrumentation \& Measurement Magazine, 2016, v. 19, i. 5, pp. 36-64

[7] S. Cass, "Anouk Wipprecht: dynamic dresses merge high fashion and technology", IEEE Spectrum, 2016, v. 53, i. 2, pp. 19-20

[8] M. Suh, K. Carroll, N. Cassill, "Critical Review on Smart Clothing Product Development", Journal of Textile and Apparel Technology and Management, 2010, v. 6, i. 4

[9] S. B. Baker, W. Xiang, I. Atkinson, "Internet of Things for Smart Healthcare: Technologies, Challenges, and Opportunities", IEEE Access, 2017, v. 5, pp. 26521-26544

[10] M. S. Hossain, G. Muhammad, "Cloud-Assisted Industrial Internet of Things (IIoT)-Enabled Framework for Health Monitoring", Computer Networks, 2016, v. 101, pp.192-202.

[11] M. Chen et al., "Smart Clothing: Connecting Human with Clouds and Big Data For Sustainable Health Monitoring”, Mobile Networks and Applications, 2016, pp. 1-21.

[12] T. Wu, F. Wu, J. Redouté, M.R. Yuce, "An Autonomous Wireless Body Area Network Implementation Towards IoT Connected Healthcare Applications" IEEE Access, 2017, v. 5, pp. 11413-11422

[13] R. H. DuHamel, D. E. Isbell, "Broadband logarithmically periodic antenna structures," IRE National Convention Record, 1957, Pt. 1, 119-128

[14] D. E. Isbell, "Nonplanar logarithmically periodic antenna structures," Tech. Rep. 30, Antenna Lab., University Illinois, Urbana, Illinois, U. S. A., 1958.

[15] R. H. DuHamel, F. R. Ore, "Logarithmically periodic antenna designs," IRE National Convention Record, Pt. 1, 1958, 139-152

[16] D. E. Isbell, "Log-periodic dipole arrays," IRE Trans. Antennas Propagat., 1960, v.8, 260-267

[17] R. L. Carrel, "Analysis and design of the log-periodic dipole antenna," Tech. Rep. 52, Antenna Lab., University Illinois, Urbana, Illinois, U. S. A., 1961.

[18] X. Wei, J. Liu, Y. Long, "Printed Log-Periodic Monopole Array Antenna With a Simple Feeding Structure", IEEE Antennas and Wireless Propagation Letters, 2018, v.17, i.1

[19] J. Ha, D. S. Filipovic, "Wideband and Efficient Slot Cavity Backing for Unidirectional Log-Periodic Antenna", IEEE Antennas and Wireless Propagation Letters, 2018, v.17, i.2, pp.299-302

[20] K. Anim, Y. Jung, "Shortened Log-Periodic Dipole Antenna Using Printed Dual-Band Dipole Elements", IEEE Transactions on Antennas and Propagation, 2018, v.66, i. 12, pp.6762-6771 
[21] Y. Ouyang, W.J. Chappell, "High Frequency Properties of Electrotextiles for Wearable Antenna Applications", IEEE Transactions on Antennas and Propagation, 2008, v. 56, n. 2, pp. 381389.

[22] I. Locher, M. Klemm, T. Kirstein, G. Tröster, "Design and Characterization of Purely Textile Patch Antennas", IEEE Transactions on Advanced Packaging, 2006, V. 29, n. 4, pp. 777-788.

23] P. Salonen, Y. Rahmat-Samii, M. Schaffrath, M. Kivikoski, "Effect of textile materials on wearable antenna performance: a case study of GPS antennas", IEEE Antennas and Propagation Society International Symposium, 2004

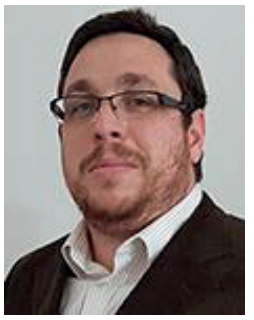

Euclides Lourenço Chuma earned a degree in Mathematics from UNICAMP (2003), graduate degree in Network and Telecommunications Systems in the INATEL (2015), and MSc in Electrical Engineering at UNICAMP (2017). Currently is $\mathrm{PhD}$ Candidate in Electrical Engineering at UNICAMP, SP-Brazil. His research interests are Antennas, Microwave, MillimeterWave, Wireless Power Transfer, Software Defined Radio and Cognitive Radio.

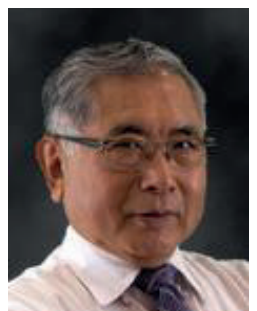

Yuzo Iano is Professor in Electrical Engineering at Unicamp and the head and founder of the Laboratory of Visual Communications since 1972. He obtained his B.Sc (1972), M.Sc (1974) and $\mathrm{PhD}(1986)$ in Electrical Engineering at University of Campinas, SP-Brazil. Research Interests: Digital Signal Processing (images/audio/video), Digital TV, 4G (LTE) and 5G Cellular Networks, Pattern Recognition, Smart Cities, Smart Grid, Internet of Things.

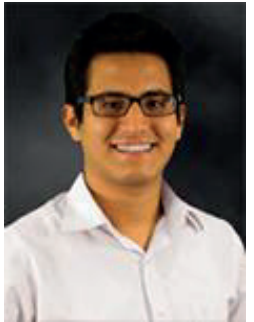

Diego Pajuelo, Graduate in Electrical Engineering from the Peruvian University of Applied Sciences (UPC), Lima, Peru in 2012. He is currently working towards his Doctoral degree in Sciences and Telecommunications at Unicamp. His research interests are: HDR Video and audio coding, Image processing, Digital television and Satellite communications.

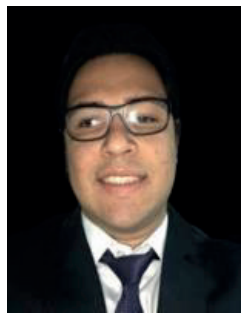

Gabriel Gomes de Oliveira, Graduated in Civil Engineering at UNIP University in 2018, studying for a Master's degree at UNICAMP, FEEC (Faculty of Electrical and Computer Engineering), DECOM (Communications Department), Laboratory of Visual Communication (LCV), currently researches and studies the area Smart City. 